\title{
Synthesis, Characterization, and Structural Assessment of Ni(II) Complexes Derived from Bis(2-hydroxy-1-naphthaldehyde)succinoyldihydrazone
}

\author{
Mithun Chakrabarty, ${ }^{1}$ Aziz Ahmed, ${ }^{2}$ and R. A. Lal $^{3}$ \\ ${ }^{1}$ Department of Chemistry, University of Technology and Management, Shillong, Meghalaya 793003, India \\ ${ }^{2}$ Department of Chemistry, Indian Institute of Technology Patna, Bihar 801103, India \\ ${ }^{3}$ Department of Chemistry, North-Eastern Hill University, Shillong, Meghalaya 793022, India \\ Correspondence should be addressed to Mithun Chakrabarty; chakrabartymc@gmail.com
}

Received 3 September 2015; Revised 2 November 2015; Accepted 3 November 2015

Academic Editor: Alfonso Castiñeiras

Copyright ( 2015 Mithun Chakrabarty et al. This is an open access article distributed under the Creative Commons Attribution License, which permits unrestricted use, distribution, and reproduction in any medium, provided the original work is properly cited.

\begin{abstract}
The monometallic nickel(II) complexes $\left[\mathrm{Ni}\left(\mathrm{H}_{2} \mathrm{nsh}\right)(\mathrm{A})_{2}\right] \cdot n \mathrm{H}_{2} \mathrm{O}$ (where $\mathrm{A}=$ water $\left(\mathrm{H}_{2} \mathrm{O}\right), n=0$ (1); pyridine (py), $n=2$ (2); 2-picoline(2-pic), $n=0$ (3); 3-picoline(3-pic), $n=2$ (4); and 4-picoline(4-pic), $n=0$ (5)) and homobimetallic nickel(II) complexes $\left[\mathrm{Ni}_{2}(\mathrm{nsh})(\mathrm{A})_{4}\right] \cdot n \mathrm{H}_{2} \mathrm{O}$ (where $\mathrm{A}=$ water $\left(\mathrm{H}_{2} \mathrm{O}\right), n=1$ (6); pyridine (py), $n=4$ (7); 2-picoline(2-pic), $n=4$ (8); 3-picoline(3-pic), $n=4$ (9); and 4-picoline(4-pic), $n=4$ (10), resp.) have been synthesized in methanol from bis(2-hydroxy-1naphthaldehyde)succinoyldihydrazone $\left(\mathrm{H}_{4} \mathrm{nsh}\right)$. The complexes have been characterized by elemental analyses, molar conductance, magnetic moment, and electronic and IR and TGA/DTA spectroscopic studies. The monometallic complexes (1) to (5) are found to have octahedral stereochemistry while complexes (6) to (10) are found to have distorted octahedral stereochemistry in which one of the $\mathrm{Ni}$ (II) centres is present in $\mathrm{N}_{2} \mathrm{O}_{2}$ coordination sphere and another $\mathrm{Ni}$ (II) centre is bonded to it through phenolate oxygen atoms via oxo-bridging.
\end{abstract}

\section{Introduction}

We have previously described the synthesis and characterization of homobimetallic $\mathrm{Mo}(\mathrm{VI})$ complexes and Ni-Zn heterobimetallic complexes derived from the ligand bis(2-hydroxy1 -naphthaldehyde)succinoyldihydrazone $[1,2]$. Nickel is another metal ion from the first transition series which has been selected for the synthesis of its complexes with the title dihydrazone and their characterization. Its selection is based on the consideration that a nickel or cobalt promoted molybdenum catalyst is important in industrial catalysis, particularly in the hydrosulfurization process [3], whereby organosulfur compounds in petroleum feedstocks are heterogeneously desulfurized with dihydrogen. Moreover nickel is also present in six types of metalloenzymes, namely, ureases, hydrogenases, methyl coenzyme $\mathrm{M}$ reductase, carbon monoxide dehydrogenase, acetyl coenzyme A synthase, and nickel superoxide dismutases [4]. Urease, the only nickel containing metallohydrolase, catalyses the hydrolysis of urea to ammonia and carbon dioxide [5]. The microbial urease from Klebsiella aerogenes has been found to contain two nickel(II) ions which are $3.5 \AA$ Apart within the dinuclear active site [4]. Further nickel occurs in heterobimetallic enzymes such as jack bean urease [6] and hydrogenase enzyme [7] in which nickel is present in combination with iron.

In addition nickel plays a prominent role in several areas of material chemistry. Some topical interplay between nickel coordination chemistry and material science exists in the use of $\mathrm{Ni}$-containing alkoxides for the synthesis of ceramic materials by MOCUD and sol-gel processes and in the preparation of nanoscopic dendrimers incorporating $\mathrm{Ni}$ and the construction of 3D hybrid inorganic-organic porous materials with $\mathrm{Ni}$ coordination units and the fabrication of 


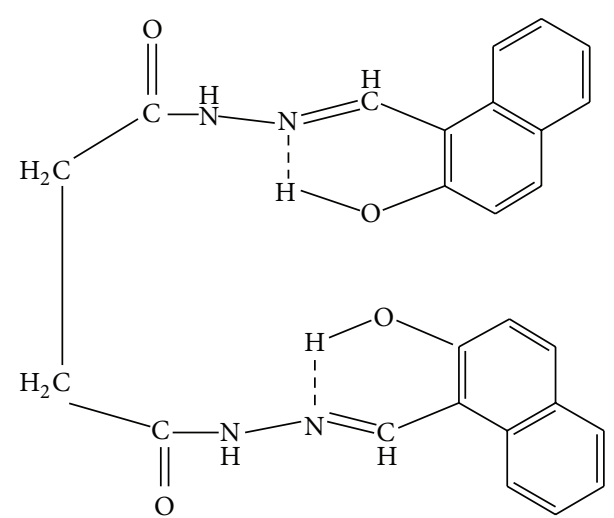

FIGURE 1: Bis(2-hydroxy-1-naphthaldehyde)succinoyldihydrazone $\left(\mathrm{H}_{4} \mathrm{nsh}\right)$.

supported Ni catalysts and Ni nanostructures through nanotechnology and paramagnetic high magnetism, culminating in the recent discovery of the first single molecule magnets based on $\mathrm{Ni}$ (II) centres [8].

A survey of literature has revealed that although metal complexes of monoacyl and aroyl- and pyridoyl-hydrazones have been studied in some greater detail [9-14], those of acyl-, aroyl-, and pyridoyl-dihydrazones have received attention in recent years $[15,16]$. In such studies, dihydrazones have been shown to enolize to different extents depending upon the mode of the preparation of the complexes, the nature of the reaction medium, the $\mathrm{pH}$ of the medium, the metal salt, and the molar ratio of the metal salt and the ligand used. Further, the reported existence of homobimetallic complexes derived from dihydrazones as ligands is quite meager [1, 17-20]. Moreover, there is only a single reported existence of homobimetallic complexes of dihydrazones containing succinoyl fraction and naphthyl fragments in their molecular skeleton $[1,2]$.

In view of the above importance of hydrazones and their metal complexes in general and nickel complexes in particular and almost virtually negligible amount of work on homobimetallic complexes of metals with dihydrazones containing succinoyl and bulky naphthyl fragments in their molecular skeleton, the present paper aims to synthesize and characterize the monometallic and homobimetallic nickels complexes obtained from bis(2-hydroxy-1-naphthaldehyde) succinoyldihydrazone $\left(\mathrm{H}_{4} \mathrm{nsh}\right)$ (Figure 1$)$.

\section{Experimental}

Chemicals are as follows: nickel acetate $\mathrm{Ni}(\mathrm{OAc})_{2}$ diethyl succinate $\left(\left(\mathrm{CH}_{2}\right)_{2}\left(\mathrm{CO}_{2} \mathrm{Et}\right)_{2}\right)$, hydrazine hydrate $\left(\mathrm{N}_{2} \mathrm{H}_{4} \cdot \mathrm{H}_{2} \mathrm{O}\right)$, 2hydroxy-1-naphthaldehyde $\left(\mathrm{C}_{10} \mathrm{H}_{6}(\mathrm{OH})(\mathrm{CHO})\right)$, pyridine, 2picoline, 3-picoline, 4-picoline, and methanol were procured commercially and were used without subsequent purification. Succinoyl dihydrazone and bis(2-hydroxy-1-naphthaldehyde)succinoyldihydrazone were prepared by using literature method as described elsewhere [1].

Physical measurements are as follows: elemental analyses $(\mathrm{C}, \mathrm{H}$, and $\mathrm{N}$ ) were performed by Perkin-Elmer 2400
CHNS/O Analyzer 11. Nickel content of the complexes was determined by literature method [21]. Infrared spectra in the range $4000-400 / 500 \mathrm{~cm}^{-1}$ were recorded on either BX-III/FT-IR Perkin-Elmer spectrophotometer or NicoletImpact 410 FT-IR Spectrophotometer with samples investigated as $\mathrm{KBr}$ discs. Room temperature magnetic susceptibility measurements were made on Sherwood Magnetic Susceptibility Balance MSB-Auto. All conductance measurements were made at $1 \mathrm{kHz}$ using Wayne Kerr B905 Automatic Precision Bridge. A dip-type conductivity cell having platinized platinum electrode was used. The cell constant was determined using a standard $\mathrm{KCl}$ solution.

\subsection{Preparation of the Complexes}

2.1.1. Preparation of $\left[\mathrm{Ni}\left(\mathrm{H}_{2} n s h\right)\left(\mathrm{H}_{2} \mathrm{O}\right)_{2}\right]$ (1). Succinoyl dihydrazine $(0.90 \mathrm{~g}, 6.16 \mathrm{mmol})$ was dissolved in hot methanol-water mixture $(50 \mathrm{~mL}, 90: 10 \mathrm{v} / \mathrm{v})$. A solution of $\mathrm{Ni}(\mathrm{OAc})_{2} \cdot 4 \mathrm{H}_{2} \mathrm{O}(1.50 \mathrm{~g}, 6.02 \mathrm{mmol})$ in methanol $(50 \mathrm{~mL})$ was added to the above solution accompanied by gentle stirring for a period of 10 minutes. The resulting solution was refluxed for 15 minutes. This solution was added to a hot solution of 2-hydroxy-1-naphthaldehyde (2.70 g, $15.70 \mathrm{mmol})$ in methanol $(100 \mathrm{~mL})$. The reaction mixture was refluxed for 1 hour which precipitated a yellow-brown compound. The complex thus obtained was filtered while hot, washed repeatedly with hot methanol and finally with ether, and dried over anhydrous $\mathrm{CaCl}_{2}$. Yield is $0.72 \mathrm{~g}$.

2.1.2. Preparation of $\left[\mathrm{Ni}\left(\mathrm{H}_{2} n s h\right)(A)_{2}\right]$, Where $A=$ Pyridine ( $p y$, 2); 2-Picoline(2-pic, 3); 3-Picoline(3-pic, 4); and 4-Picoline(4pic, 5). Complex $\left[\mathrm{Ni}\left(\mathrm{H}_{2} \mathrm{nsh}\right)\left(\mathrm{H}_{2} \mathrm{O}\right)_{2}\right]$ (1) $(1.00 \mathrm{~g}, 1.86 \mathrm{mmol})$ was suspended in methanol $(100 \mathrm{~mL})$ accompanied by gentle stirring for 10 minutes at $50-60^{\circ} \mathrm{C}$. To this suspension, pyridine $(1.50 \mathrm{~mL}, 18.10 \mathrm{mmol})$ was added maintaining the molar ratio at $1: 10$. The reaction mixture was refluxed for $3 \mathrm{hrs}$ which precipitated the light brown compound. The compound thus obtained was filtered, washed repeatedly with hot methanol and then with ether, and dried over anhydrous $\mathrm{CaCl}_{2}$. Yield is $0.70 \mathrm{~g}$.

Complexes (3), (4), and (5) were also prepared in the same manner using 2-picoline, 3-picoline, and 4-picoline instead of pyridine and maintaining the metal: base ratio at $1: 10$,

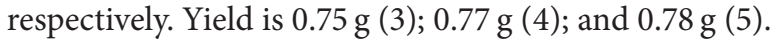

2.1.3. Preparation of $\left[\mathrm{Ni}_{2}(n s h)\left(\mathrm{H}_{2} \mathrm{O}\right)_{4}\right]$ (6). The dihydrazone $\left(\mathrm{H}_{4} \mathrm{nsh}\right)(1.00 \mathrm{~g}, 2.20 \mathrm{mmol})$ was suspended in methanol $(100 \mathrm{~mL})$ and stirred for 30 minutes at $60^{\circ} \mathrm{C}$. To this was added a solution of $\mathrm{Ni}(\mathrm{OAc})_{2} \cdot 4 \mathrm{H}_{2} \mathrm{O}(1.65 \mathrm{~g}, 6.63 \mathrm{mmol})$ in methanol $(50 \mathrm{~mL})$ maintaining the molar ratio at $1: 3$. The reaction mixture was refluxed for $3 \mathrm{hrs}$, which precipitated a brown compound. The compound thus obtained was filtered while hot, washed repeatedly with hot methanol and finally with ether, and dried over anhydrous $\mathrm{CaCl}_{2}$. Yield is $0.65 \mathrm{~g}$.

2.1.4. Preparation of $\left[N i_{2}(n s h)(A)_{4}\right]$, Where $A=$ Pyridine ( $p y$, 7); 2-Picoline(2-pic, 8); 3-Picoline(3-pic, 9); and 4-Picoline(4pic, 10). Complex $\left[\mathrm{Ni}_{2}(\mathrm{nsh})\left(\mathrm{H}_{2} \mathrm{O}\right)_{2}\right](6)(1.00 \mathrm{~g}, 1.55 \mathrm{mmol})$ 
was suspended in methanol $(100 \mathrm{~mL})$ by gentle heating at $60^{\circ} \mathrm{C}$. To this suspension pyridine $(1.24 \mathrm{~mL}, 15.42 \mathrm{mmol})$ was added maintaining the molar ratio at $1: 10$. The reaction mixture was refluxed for 2 hours. The resulting precipitate was isolated in the usual way. Complexes (7) to (10) were also synthesized by essentially following the above procedure using 2-picoline, 3-picoline, and 4-picoline instead of pyridine maintaining the metal : base molar ratio at $1: 10$, respectively. Yield is $0.61 \mathrm{~g}(7) ; 0.65 \mathrm{~g}(8) ; 0.67 \mathrm{~g}(9)$; and $0.64 \mathrm{~g}(10)$.

\section{Results and Discussion}

The complexes described in the present paper together with their molecular formulae, colour, decomposition point, percentage yield, analytical data, magnetic moment, molar conductance, and electronic spectral data for the complexes have been shown in Table 1 . The composition of the complexes has been deduced on the basis of elemental analysis as follows:

$\left[\mathrm{Ni}\left(\mathrm{H}_{2} \mathrm{nsh}\right)(\mathrm{A})_{2}\right] \cdot n \mathrm{H}_{2} \mathrm{O}(n=0,2)\left(\mathrm{A}=\mathrm{H}_{2} \mathrm{O}(1)\right.$, py (2), 2-pic (3), 3-pic (4), and 4-pic (5)) and $\left[\mathrm{Ni}_{2}(\mathrm{nsh})(\mathrm{A})_{4}\right] \cdot n \mathrm{H}_{2} \mathrm{O}(n=1,4)\left(\mathrm{A}=\mathrm{H}_{2} \mathrm{O}(6)\right.$, py (7), 2-pic (8), 3-pic (9), and 4-pic (10)). The complexes are brown, yellow, light brown, and dark yellow in colour. All of the complexes are air stable and decompose above $300^{\circ} \mathrm{C}$ without melting. All of the complexes are insoluble in water and common organic solvents such as ethanol, methanol, chloroform, benzene, hexane, and ether. However, all of the complexes are soluble in DMF and DMSO.

3.1. Thermal/TGA/DTA Studies. None of the $1: 1$ (metal: ligand) complexes except complexes (2) and (4) show weight loss at $110^{\circ} \mathrm{C}$ ruling out the possibility of presence of lattice water in their structure. The $1: 1$ (metal: ligand) complexes (2) and (4) show weight losses at $110^{\circ} \mathrm{C}$ corresponding to two water molecules while all of the $2: 1$ (metal: ligand) complexes show weight losses at $110^{\circ} \mathrm{C}$ corresponding to four water molecules except complex (1) which shows weight loss corresponding to one water molecule at this temperature. The loss of these water molecules at this temperature suggests that they are present in the lattice structure of the complexes. Further, complexes (1) and (6) show loss of weight corresponding to two and four water molecules at $180^{\circ} \mathrm{C}$ suggesting the presence of two and four water molecules in their first coordination sphere around the metal centres, respectively. On the other hand, complexes (2) to (5) show weight loss corresponding to two pyridine/2-picoline/3-picoline/4picoline molecules while complexes (7) to (10) show weight loss corresponding to four pyridine/2-picoline/3-picoline/4picoline molecules at $220^{\circ} \mathrm{C}$. The expulsion of these donor molecules at such a higher temperature indicates that they are coordinated with the metal centre.

The loss of neutral molecules at such a high temperature may indicate their presence in the coordination sphere around the metal centre but the classification of solvent molecules on the basis of TGA alone as being held in the lattice or being coordinated with the metal centre needs utmost caution in view of the fact that the loss of solvent molecules at considerable high temperature might occur due to hydrogen bond network in the solid state of the complexes that might permeate the lattice.

The vapours evolved at temperatures $110^{\circ} \mathrm{C}, 180^{\circ} \mathrm{C}$, and $220^{\circ} \mathrm{C}$ in all complexes have been identified except complexes (3) and (8) by passing through a trap containing anhydrous copper sulfate and test tubes containing solution of sodium hydroxide and chloroform, $\mathrm{I}_{2}$ and sodium hydroxide and cyanogen bromide, respectively $[22,23]$. The vapours evolved at $110^{\circ} \mathrm{C}$ in complexes (2), (4), and (6) to (10) and at $180^{\circ} \mathrm{C}$ in complex (1) and in both temperature ranges in complex (6) turned anhydrous copper sulfate blue confirming that they originate from water molecules. The vapours evolved in complexes (2) and (7) at $220^{\circ} \mathrm{C}$ turned the $\mathrm{CHCl}_{3}$ and $\mathrm{NaOH}$ solution red [24]. This confirmed that they originate from pyridine molecules. Similarly, the vapours evolved from complexes (4), (5), (9), and (10) at this temperature turned the colour of cyanogens bromide solution to green violet and blue, respectively, on treatment with phloroglucinol solution. This suggests the presence of 2-picoline and 4picoline molecules in complexes (4), (5), (9), and (10), respectively. The weight loss corresponds to two pyridine/3picoline/4-picoline molecules in complexes (2), (4), and (5) and to four pyridine/3-picoline/4-picoline molecules in complexes (6), (9), and (10) lending credence to the suggested number of pyridine/3-picoline/4-picoline molecules in the first coordination sphere of these complexes.

Thermal properties of the mononuclear complex $\left[\mathrm{Ni}\left(\mathrm{H}_{2} \mathrm{nsh}\right)\left(\mathrm{H}_{2} \mathrm{O}\right)_{2}\right]$ (1) and the binuclear complexes $\left[\mathrm{Ni}(\mathrm{nsh})(\mathrm{A})_{4}\right] \cdot n \mathrm{H}_{2} \mathrm{O}\left(\mathrm{A}=\mathrm{H}_{2} \mathrm{O}(6)\right.$, py (7), and 2-pic (8)) were investigated as representative samples by thermogravimetric analysis and differential thermal analysis. Figures 7-10 (Supplementary Data in Supplementary Material available online at http://dx.doi.org/10.1155/2015/121895) present the recorded TGA/DTA curves of the four metal complexes under dinitrogen atmosphere. The essential common feature of all the complexes is that once they start losing weight, they give no indication of their stability at any point of their decomposition unless they are converted into metal oxide in the final stage. It can be seen that the TGA curves of complex (1) show no weight loss up to $200^{\circ} \mathrm{C}$ indicating absence of water molecules and any other absorptive solvent molecules in the complex. At a temperature of $200^{\circ} \mathrm{C}$, a weight loss process commences and weight loss (exp.: 6.0\%) equal to two water molecules (theo.: 6.59\%) is completed up to a temperature of about $290^{\circ} \mathrm{C}$. The water molecules lost in this temperature range indicate that they are coordinated with the metal centre. The most important decomposition step in the complex occurs in the temperature range $295-650^{\circ} \mathrm{C}$ in which weight loss of about $78.27 \%$ is observed. The ultimate product of the decomposition reaction is metallic oxide. The thermogram shows that once the decomposition of the complex has commenced at $200^{\circ} \mathrm{C}$, it continues until the complex is converted into metallic oxide at a temperature of about $650^{\circ} \mathrm{C}$. The loss of coordinated water molecules and ligand occurs in a single simultaneous step.

Complex $\left[\mathrm{Ni}_{2}(\mathrm{~L})\left(\mathrm{H}_{2} \mathrm{O}\right)_{4}\right] \cdot \mathrm{H}_{2} \mathrm{O}(6)$ shows essentially two decomposition steps in the temperature range $85-730^{\circ} \mathrm{C}$. The TGA curve of the complex starts showing mass loss 


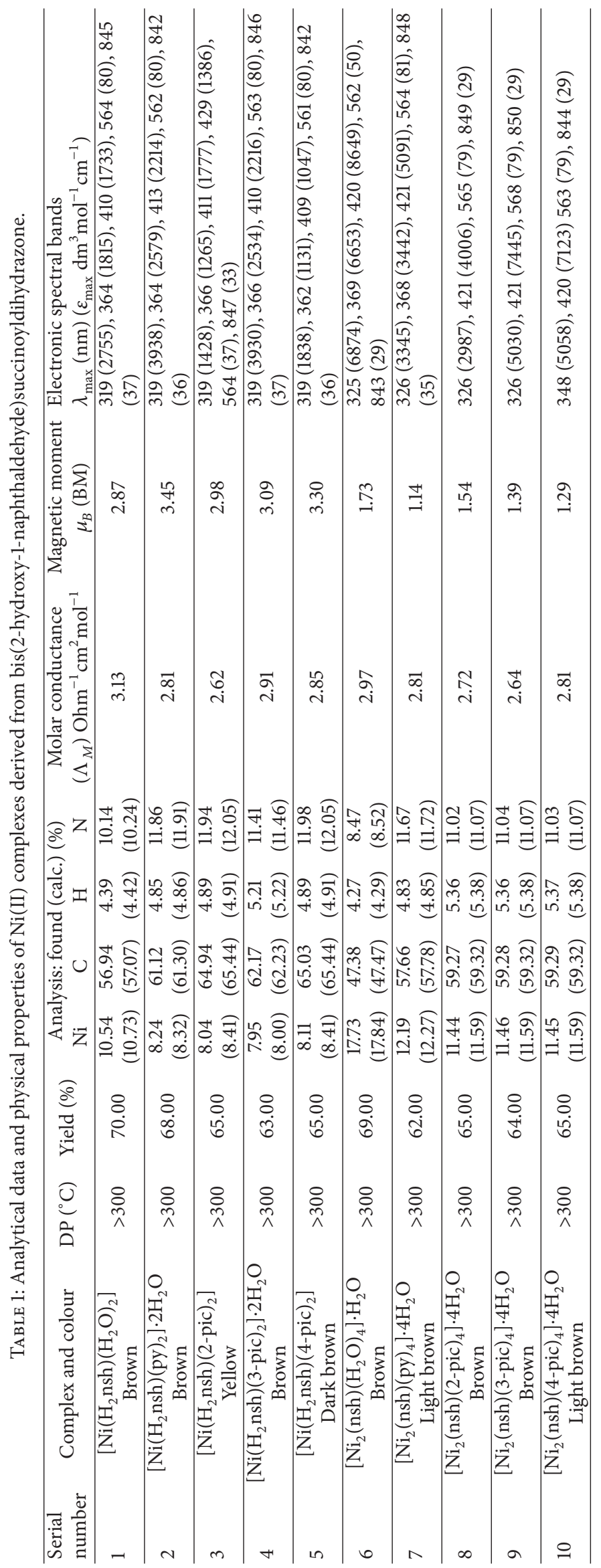


at $85^{\circ} \mathrm{C}$ which continues up to $152^{\circ} \mathrm{C}$. In this temperature range the complex shows mass loss equal to $2.80 \%$ which corresponds to one water molecule (theo.: $2.74 \%$ ) signifying that it is present in the lattice structure of the complex. After this, another decomposition step commences which lasts up to $370^{\circ} \mathrm{C}$. The mass loss in this temperature range corresponds to loss of four water molecules (exp.: 10.70\%; theo.: $10.95 \%$ ). The loss of water molecules in this temperature range suggests that they are coordinated with the metal centre. The loss of lattice and coordinated water molecules occurs in a single continuous step which suggests that those water molecules are hydrogen bonded to ligand as well as to one another which permeates the lattice. The last step which commences after $370^{\circ} \mathrm{C}$ corresponds to the loss of coordinated ligand molecule devoid of two oxygen atoms (exp.: 64.77\%; theo.: 63.89\%). The weight loss in the temperature range $370-510^{\circ} \mathrm{C}$ is equal to $38.47 \%$ which corresponds to loss of two-naphthaldehyde fraction (theo.: $38.33 \%$ ) of the coordinated ligand. The remaining part of the ligand decomposes after $510^{\circ} \mathrm{C}$ until it is converted to metal oxide at $731^{\circ} \mathrm{C}$. The percentage weight of the final residue is $21.67 \%$ which corresponds to two $\mathrm{NiO}$ molecules (theo.: 22.72\%). Complexes (7) and (8) show almost similar decomposition behavior. The thermograms of the complexes show three decomposition steps within the temperature range 100$694^{\circ} \mathrm{C}$. In complex $\left[\mathrm{Ni}_{2}(\mathrm{~L})(\mathrm{py})_{4}\right] \cdot 4 \mathrm{H}_{2} \mathrm{O}$ (7) the first step of decomposition occurs in the temperature range $200-410^{\circ} \mathrm{C}$ which corresponds to four water and two pyridine molecules (exp.: 24.75\%; theo.: 24.07\%) in the temperature range $200-$ $400^{\circ} \mathrm{C}$ while, in complex $\left[\mathrm{Ni}_{2}(\mathrm{~L})(2 \text {-pic })_{4}\right] \cdot 4 \mathrm{H}_{2} \mathrm{O}(8)$, the first stage in the temperature range $100-400\left[\mathrm{Ni}_{2}(\mathrm{~L})(\mathrm{py})_{4}\right] \cdot 4 \mathrm{H}_{2} \mathrm{O}$ (7) corresponds to the loss of four water molecules and one 2-picoline molecule (exp.: 16.85\%; theo.: 16.39\%). The next stage involves the loss of two pyridine molecules (exp.: 16.42\%; theo.: $16.59 \%)$ in complex (7) and three 2-picoline molecules (exp.: $27.85 \%$; theo.: $27.59 \%$ ) in the temperature range $400-440^{\circ} \mathrm{C}$ in complex (8). The last step involves the decomposition of the coordinated ligand (exp.: $43.79 \%$; theo.: $43.96 \%$ ) devoid of two oxygen atoms in complex (7) in the temperature range $440-630^{\circ} \mathrm{C}$. In fact the water molecules are lost in the temperature range $200-275^{\circ} \mathrm{C}$ in complex (7) (exp.: 7.85\%; theo.: $7.54 \%$ ) and in the temperature range $1230-235^{\circ} \mathrm{C}$ in complex (8) (exp.: 6.45\%; theo.: 7.12\%). The complexes show endothermic peaks centred at 265 and $210^{\circ} \mathrm{C}$, respectively, signifying that these water molecules are present in the lattice of the complexes. The two pyridine molecules and one 2-picoline molecule are lost subsequently in the temperature range of $275-410^{\circ} \mathrm{C}$ and $235-400^{\circ} \mathrm{C}$, respectively. The loss of pyridine and 2-picoline molecules and the coordinated ligand are characterized by broad exothermic peaks in the DTA curve of the complex.

3.2. Molar Conductance. The molar conductance values of complexes (1) to (10) in DMSO solution at $10^{-3} \mathrm{M}$ dilution fall in the range $2.62-3.13 \mathrm{ohm}^{-1} \mathrm{~cm}^{2} \mathrm{~mol}^{-1}$ suggesting that they are nonelectrolytes in this solvent [25].

3.3. Magnetic Moment. The $\mu_{B}(\mathrm{BM})$ values for complexes (1) to (10) are set out in Table 1. The effective electronic configuration of nickel(II) is $3 \mathrm{~d}^{8}$ and exhibits a magnetic moment higher than that expected for two unpaired electrons in an octahedral and a tetrahedral environment, whereas diamagnetism of the nickel(II) complexes leads to square planar stereochemistry. The effective magnetic moment reported for high-spin octahedral $\mathrm{Ni}(\mathrm{II})$ complexes is in the range 3.00$3.50 \mathrm{BM}$, while for the tetrahedral complexes it ranges from 3.5 to $4.0 \mathrm{BM}$. The reason for this deviation is attributed to spin-orbit coupling which causes an orbital contribution in the quenched ${ }^{3} \mathrm{~A}_{2 g}$ ground state of $\mathrm{Ni}(\mathrm{II})$ ion in an octahedral environment and not due to contribution from the orbital angular momentum of the electrons because the orbital angular momentum does not affect ${ }^{3} \mathrm{~A}_{2 \mathrm{~g}}$ state. On the contrary, in case of a tetrahedral $\mathrm{Ni}(\mathrm{II})$ complex, the orbital angular momentum contributes strongly to the magnetic moment leading to magnetic moment values as high as 4.0 BM. The paramagnetism of nickel(II) complexes (1) to (5) rules out the possibility of square planar structure and tetrahedral structure can be discarded on the basis of the magnitude of the magnetic moment. Complexes (1) to (5) have magnetic moment values in the region of 2.85-3.45 BM which is typical of an octahedral $\mathrm{Ni}(\mathrm{II})$ compound $[26,27]$.

In homobimetallic $\mathrm{Ni}$ (II) complexes (6) to (10), two $\mathrm{Ni}(\mathrm{II})$ ions are present for each ligand molecule and the resulting complexes have magnetic moment values in the region of 1.14-1.73 BM, that is, $0.5-0.87 \mathrm{BM}$ per metal(II) ion. Such low values of magnetic moment in complexes (6) to (10) certainly rule out low-spin square planar stereochemistry for the complexes. But these values are considerably less than the values reported for spin-free nickel(II) complexes indicating a strong metal-metal interaction in the structural unit. Anomalous magnetic moment values in the solid state have been explained on the basis of absorption spectra by proposing a mixed octahedral and square planar stereochemistry in the solid state due to molecular association [2831], but the electronic absorption spectra of the complexes described in this paper are consistent with the tetragonally distorted octahedral stereochemistry. Since the hydrazine bridges do not cause any lowering of the magnetic moment [21], therefore it is still reasonable to believe that the lowering of the magnetic moment is due to the presence of oxo-bridged structure and as a result of this $\mathrm{Ni}(\mathrm{II})$ complexes attain a tetragonally distorted octahedral stereochemistry.

3.4. Electronic Spectra. The electronic spectra of the ligand and its $\mathrm{Ni}(\mathrm{II})$ complexes were recorded in DMF solution because of poor solubility of the ligand and the complexes in common organic solvents. The important electronic spectral bands for the dihydrazone ligand $\left(\mathrm{H}_{4} \mathrm{nsh}\right)$ and the monometallic and homobimetallic $\mathrm{Ni}(\mathrm{II})$ complexes along with their molar extinction coefficient are presented in Table 1. The free ligand $\mathrm{H}_{4}$ nsh exhibits a couple of bands in the region of $317 \mathrm{~nm}$ and $363 \mathrm{~nm}$. The band at $317 \mathrm{~nm}$ is assigned to intraligand $\pi \rightarrow \pi^{*}$ transition while the band at $363 \mathrm{~nm}$ is assigned to $n \rightarrow \pi^{*}$ transition [32-34].

The electronic spectra of the complexes exhibit two to four bands in the region of $300-450 \mathrm{~nm}$. The bands appearing in the region of $319-370 \mathrm{~nm}$ are attributed to intraligand transitions which exhibit red shift on complexation. The red 
TABLE 2: Ligand field parameters for Ni(II) complexes derived from bis(2-hydroxy-1-naphthaldehyde)succinoyldihydrazone.

\begin{tabular}{|c|c|c|c|c|c|c|c|c|c|c|c|}
\hline \multirow[t]{2}{*}{$\begin{array}{l}\text { Serial } \\
\text { number }\end{array}$} & \multirow[t]{2}{*}{ Complex } & \multicolumn{2}{|c|}{$\begin{array}{c}{ }^{3} \mathrm{~A}_{2 \mathrm{~g}} \rightarrow{ }^{3} \mathrm{~T}_{2 \mathrm{~g}}(\mathrm{~F}) \\
\left(\nu_{1}\right)\end{array}$} & \multicolumn{2}{|c|}{$\begin{array}{c}{ }^{3} \mathrm{~A}_{2 \mathrm{~g}} \rightarrow{ }^{3} \mathrm{~T}_{1 \mathrm{~g}}(\mathrm{~F}) \\
\left(\nu_{2}\right)\end{array}$} & \multirow[t]{2}{*}{$\begin{array}{c}\mathrm{Dq} \\
\left(\mathrm{cm}^{-1}\right)\end{array}$} & \multirow[t]{2}{*}{$v_{2} / \nu_{1}$} & \multirow[t]{2}{*}{$B\left(\mathrm{~cm}^{-1}\right)$} & \multirow[t]{2}{*}{$\beta$} & \multirow[t]{2}{*}{$\beta^{\circ}(\%)$} & \multirow[t]{2}{*}{$\begin{array}{c}\text { LFSE } \\
\left(\mathrm{kcal} \mathrm{mol}^{-1}\right)\end{array}$} \\
\hline & & $\mathrm{nm}$ & $\mathrm{cm}^{-1}$ & $\mathrm{~nm}$ & $\mathrm{~cm}^{-1}$ & & & & & & \\
\hline 1 & {$\left[\mathrm{Ni}\left(\mathrm{H}_{2} \mathrm{nsh}\right)\left(\mathrm{H}_{2} \mathrm{O}\right)_{2}\right]$} & 845 & 11834 & 564 & 17730 & 1183.4 & 1.498 & 653.57 & 0.6278 & 37.22 & 40.66 \\
\hline 2 & {$\left[\mathrm{Ni}\left(\mathrm{H}_{2} \mathrm{nsh}\right)(\mathrm{py})_{2}\right] \cdot 2 \mathrm{H}_{2} \mathrm{O}$} & 842 & 11876 & 562 & 17794 & 1187.6 & 1.4983 & 656.09 & 0.6302 & 36.98 & 40.80 \\
\hline 3 & {$\left[\mathrm{Ni}\left(\mathrm{H}_{2} \mathrm{nsh}\right)(2-\mathrm{pic})_{2}\right]$} & 847 & 11806 & 564 & 17730 & 1180.6 & 1.5017 & 659.79 & 0.6338 & 36.62 & 40.56 \\
\hline 4 & {$\left[\mathrm{Ni}\left(\mathrm{H}_{2} \mathrm{nsh}\right)(3-\mathrm{pic})_{2}\right] \cdot 2 \mathrm{H}_{2} \mathrm{O}$} & 846 & 11820 & 563 & 17762 & 1182 & 1.5027 & 662.63 & 0.6365 & 36.35 & 40.61 \\
\hline 5 & {$\left[\mathrm{Ni}\left(\mathrm{H}_{2} \mathrm{nsh}\right)(4-\mathrm{pic})_{2}\right]$} & 842 & 11876 & 561 & 17825 & 1187.6 & 1.5009 & 661.81 & 0.6357 & 36.43 & 40.80 \\
\hline 6 & {$\left[\mathrm{Ni}_{2}(\mathrm{nsh})\left(\mathrm{H}_{2} \mathrm{O}\right)_{4}\right] \cdot \mathrm{H}_{2} \mathrm{O}$} & 843 & 11862 & 562 & 17794 & 1186.2 & 1.5001 & 659.18 & 0.6332 & 36.68 & 40.75 \\
\hline 7 & {$\left[\mathrm{Ni}_{2}(\mathrm{nsh})(\mathrm{py})_{4}\right] \cdot 4 \mathrm{H}_{2} \mathrm{O}$} & 848 & 11792 & 564 & 17730 & 1179.2 & 1.5035 & 662.95 & 0.6368 & 36.32 & 40.51 \\
\hline 8 & {$\left[\mathrm{Ni}_{2}(\mathrm{nsh})(2-\mathrm{pic})_{4}\right] \cdot 4 \mathrm{H}_{2} \mathrm{O}$} & 849 & 11779 & 565 & 17699 & 1177.9 & 1.5025 & 660.07 & 0.6341 & 36.59 & 40.47 \\
\hline 9 & {$\left[\mathrm{Ni}_{2}(\mathrm{nsh})(3-\mathrm{pic})_{4}\right] \cdot 4 \mathrm{H}_{2} \mathrm{O}$} & 850 & 11765 & 566 & 17606 & 1176.5 & 1.4964 & 645.98 & 0.6205 & 37.95 & 40.42 \\
\hline 10 & {$\left[\mathrm{Ni}_{2}(\mathrm{nsh})(4-\mathrm{pic})_{4}\right] \cdot 4 \mathrm{H}_{2} \mathrm{O}$} & 844 & 11848 & 563 & 17762 & 1184.8 & 1.4991 & 656.37 & 0.6302 & 36.98 & 40.70 \\
\hline
\end{tabular}

shift of the ligand bands gives good evidence of chelation of dihydrazone to the metal centre. All of the complexes show new band in the region of 410-440 $\mathrm{nm}$ which has very high molar extinction coefficient. In view of very high molar extinction coefficient of this band, it is assigned to have its origin in the ligand-to-metal charge-transfer transition. This band arises most probably from charge-transfer transition from naphtholate oxygen atoms to the metal centre $[16,35$, 36]. This ligand-to-metal charge-transfer band is strongly influenced by the chemical nature of the ligand within a given stereochemistry and is responsible for the appearance of orange colour of the complexes.

In an octahedral environment, $\mathrm{Ni}(\mathrm{II})$ complexes exhibit three bands which are assigned to ${ }^{3} \mathrm{~A}_{2 \mathrm{~g}} \rightarrow{ }^{3} \mathrm{~T}_{2 \mathrm{~g}}(\mathrm{~F})\left(\nu_{1}\right)$; ${ }^{3} \mathrm{~A}_{2 \mathrm{~g}} \rightarrow{ }^{3} \mathrm{~T}_{1 \mathrm{~g}}(\mathrm{~F})\left(\nu_{2}\right)$; and ${ }^{3} \mathrm{~A}_{2 \mathrm{~g}} \rightarrow{ }^{3} \mathrm{~T}_{1 \mathrm{~g}}(\mathrm{P})\left(\nu_{3}\right)$ transitions, respectively. Since the transition ${ }^{3} \mathrm{~A}_{2 \mathrm{~g}} \rightarrow{ }^{3} \mathrm{~T}_{1 \mathrm{~g}}(\mathrm{P})\left(\nu_{3}\right)$ generally occurs in the region of $330-400 \mathrm{~nm}$ in which the bands due to organic fraction of the complexes arise as well, hence, this region is not useful from the point of view of drawing any conclusion about the stereochemistry around the $\mathrm{Ni}(\mathrm{II})$ centre. However, the first two low energy bands observed in the region of 500-900 $\mathrm{nm}$ in all of the complexes are characteristic of nickel(II) in octahedral environment. The octahedral geometry of $\mathrm{Ni}$ (II) complexes is further supported by the value of $v_{2} / \nu_{1}$ ratio which lies in the region of 1.498-1.504 [26, 37].

Various ligand field parameters (Table 2), namely, Racah interelectronic repulsion parameter $(B)$, ligand field splitting energy (10 Dq), covalency factor $(\beta)$, and ligand field stabilization energy (LFSE), have been calculated for the $\mathrm{Ni}$ (II) complexes.

The ligand field splitting energy $(10 \mathrm{Dq})$ and the Racah interelectronic repulsion parameter $(B)$ were calculated by the equations given by Lever [38]. Consider

$$
\begin{aligned}
{ }^{3} \mathrm{~A}_{2 \mathrm{~g}} & \longrightarrow{ }^{3} \mathrm{~T}_{2 \mathrm{~g}}(\mathrm{~F}),\left(v_{1}\right)=10 \mathrm{Dq} \\
{ }^{3} \mathrm{~A}_{2 \mathrm{~g}} & \longrightarrow{ }^{3} \mathrm{~T}_{1 \mathrm{~g}}(\mathrm{~F}),\left(v_{2}\right) \\
= & 7.5 B+15 \mathrm{Dq} \\
& -\frac{1}{2}\left(225 B^{2}+100 \mathrm{Dq}^{2}-180 \mathrm{Dq} B\right)^{1 / 2}
\end{aligned}
$$

$$
\begin{aligned}
{ }^{3} \mathrm{~A}_{2 \mathrm{~g}} & \longrightarrow{ }^{3} \mathrm{~T}_{1 \mathrm{~g}}(\mathrm{P}),\left(v_{3}\right) \\
= & 7.5 B+15 \mathrm{Dq} \\
& +\frac{1}{2}\left(225 B^{2}+100 \mathrm{Dq}^{2}-180 \mathrm{Dq} B\right)^{1 / 2}
\end{aligned}
$$

The Racah interelectronic repulsion parameter $(B)$ was also calculated by the following equation [39] and the values obtained were found to be the same as calculated from the equations given by Lever:

$$
B_{\text {Complex }}=\frac{\left(2 v_{1}^{2}+v_{2}^{2}-3 v_{1} v_{2}\right)}{\left(15 v_{2}-27 v_{1}\right)}
$$

The covalency factor $(\beta)$ was obtained by the following equation:

$$
\beta=\frac{B}{B^{\prime}} \quad\left(B^{\prime} \text { is the free ion value }=1038 \mathrm{~cm}^{-1}\right) .
$$

The ligand field stabilization energy (LFSE) is expressed by the following equation:

$$
\mathrm{LFSE}=12 \mathrm{Dq} .
$$

The percentage lowering of energy of "P" state in the complexes as compared to its value in the free gaseous ion $\left(\beta^{\circ}\right)$ is obtained by the following equation:

$$
\beta^{\circ}=100-(\beta \times 100) \text {. }
$$

The energy of first transition for complexes (1) to (10) lies in the range of $11765-11876 \mathrm{~cm}^{-1}$ which is equal to $10 \mathrm{Dq}$. The evaluation of Racah interelectronic repulsion parameter " $B$ " from the expression of $\nu_{1}$ gave values which lie in the range of 645-662. These values are very low as compared to the free ion value $\left(1038 \mathrm{~cm}^{-1}\right)$. This indicates that all of the complexes have considerable covalent character. The nephelauxetic ratio, $\beta$, for the complexes lies in the range of $0.62-0.64$. The obtained $\beta$ value being less than unity suggests the presence of considerable amount of covalent character in the metalligand bonds. The percentage lowering of energy of " $\mathrm{P}$ " state 
in the complexes as compared to its value in the free gaseous ion, that is, $\beta^{\circ}$, lies in the range of $36.32-37.95 \%$ which shows a high degree of covalency.

The $v_{2} / \nu_{1}$ values for tetragonal complexes are found significantly higher than the usual range for octahedral complexes and sometimes greater than the theoretical limit of 1.80 for octahedral symmetry. The interaction between ${ }^{3} \mathrm{~T}_{1 \mathrm{~g}}$ (P) and ${ }^{3} \mathrm{~T}_{1 \mathrm{~g}}(\mathrm{~F})$ states [40] gradually lowers the ratio of $\nu_{2} / \nu_{1}$ from the theoretical value of 1.80 to $1.50-1.70$ and values in the range of 1.60-1.70 are common for nickel(II) complexes of octahedral symmetry. In the present complexes $\nu_{2} / \nu_{1}$ values lie in the range of 1.49-1.50 which are slightly lower than the lower limit of usual octahedral complexes but are within the range reported for octahedral nickel(II) complexes [41]. These low values indicate a strong interaction between ${ }^{3} \mathrm{~T}_{1 \mathrm{~g}}$ (P) and ${ }^{3} \mathrm{~T}_{1 \mathrm{~g}}$ (F) states of the complexed nickel(II) ion. The value of ligand field stabilization energy for the complexes lies in the range of $40.42-40.80 \mathrm{kcal} \mathrm{mol}^{-1}$.

3.5. Infrared Spectra. The uncoordinated dihydrazone shows a medium intensity broad band centred at $3423 \mathrm{~cm}^{-1}$ and a medium intensity band at $3244 \mathrm{~cm}^{-1}$ (Table 3 ). The band at $3423 \mathrm{~cm}^{-1}$ has been assigned to $v(\mathrm{OH})$ vibration of 2 hydroxy-1-naphthaldehyde part of the dihydrazone, while the band at $3244 \mathrm{~cm}^{-1}$ is assigned to arise from secondary $-\mathrm{NH}$ group. The IR spectra of the complexes show a weak-tomedium intensity band in the region of $3000-3500 \mathrm{~cm}^{-1}$. This band is attributed to stretching vibrations of water molecules absorbed by $\mathrm{KBr}$ during pellet preparation. However, these bands appear to have contribution from coordinated water molecules in complexes (1) and (6). The band in the region of $3000-3500 \mathrm{~cm}^{-1}$ in complexes (1) to (5) also appears to have contribution from the stretching vibration of coordinated naphtholic $-\mathrm{OH}$ group. Further, the spectral features of complexes (6) to (10) conspicuously indicate the coordination of naphtholic $-\mathrm{OH}$ group via deprotonation to the metal centre in these complexes.

None of the complexes shows the band characteristic of $\nu \mathrm{NH}$ vibration. This suggests the destruction of $-\mathrm{NH}$ group as a result of enolization of the ligand in the complexes and its coordination with the metal centre in the enol form.

The $\nu(\mathrm{C}=\mathrm{O})$ stretching vibration appears as a very strong band at $1672 \mathrm{~cm}^{-1}$ in the infrared spectrum of the uncoordinated dihydrazone. In the infrared spectra of all the complexes, the amide I band disappears indicating destruction of amide structure of the ligand and its coordination through carbonyl oxygen atoms (in enol form) to the metal centre.

The $v(\mathrm{C}=\mathrm{N})$ band appears as a couple of bands in the region of $1622-1602 \mathrm{~cm}^{-1}$ in the IR spectra of the complexes similar to that in the uncoordinated dihydrazone. This band registers an average downward shift of $2-3 \mathrm{~cm}^{-1}$ indicating coordination of dihydrazone through azomethine nitrogen atom with the metal centre $[42,43]$. This downward shift of $v(\mathrm{C}=\mathrm{N})$ band is attributed to the drainage of electron density from azomethine nitrogen atom to the metal centre. The existence of two $v(\mathrm{C}=\mathrm{N})$ bands in the complexes shows that the two azomethine nitrogen groups are inequivalent suggesting that the strengths of the two $\mathrm{M} \leftarrow \mathrm{N}$ bands are not the same. Further, the differences between the two $v(\mathrm{C}=\mathrm{N})$ stretching frequencies are of the order of $13-18 \mathrm{~cm}^{-1}$ which is the reported range of absorption for molecules with anti-cis configuration. [44]. This suggests that the dihydrazone exists in the anti-cis configuration in these complexes.

A weak but intense band at $1508 \mathrm{~cm}^{-1}$ in the IR spectra of the complexes is attributed to stretching vibration of newly created $\mathrm{NCO}^{-}$group produced as a result of enolization of the ligand $[42,43]$.

The medium intensity band at $1281 \mathrm{~cm}^{-1}$ due to $v(\mathrm{C}-\mathrm{O})$ shifts to higher frequency by $21 \mathrm{~cm}^{-1}$ in complexes (1) to (5) and appears as $\sim 1303 \mathrm{~cm}^{-1}$ as a medium intensity band. On the other hand this band splits into two bands in complexes (6) to (10). One of the bands remains almost at the same position in the complexes as compared to that in the free ligand while the other band shifts to higher position by $21 \mathrm{~cm}^{-1}$ and appears around $1303 \mathrm{~cm}^{-1}$ as a medium intensity band. Such a feature associated with $v(\mathrm{C}-\mathrm{O})$ band indicates bonding through $\mathrm{C}-\mathrm{O}$ oxygen atoms to the metal centre $[42,43]$.

It has been found that the $\nu(\mathrm{N}-\mathrm{N})$ band appears in the region of $1040-970 \mathrm{~cm}^{-1}$ in the metal complexes derived from N,N-diacyl hydrazines [44]. Eliminating the bands due to $\mathrm{C}-\mathrm{H}$ in-plane deformation in the region of $1050-900 \mathrm{~cm}^{-1}$, a weak band at $1029 \mathrm{~cm}^{-1}$ in the present ligand has been assigned to $v(\mathrm{~N}-\mathrm{N})$. This band shifts to higher frequency by $14-27 \mathrm{~cm}^{-1}$ in all of the metal complexes. This indicates the involvement of nitrogen atom of $\mathrm{N}-\mathrm{N}$ group in coordination with the metal centre [45]. Complexes (6) to (10) show an additional band in the region of $861-897 \mathrm{~cm}^{-1}$ and it is assigned to have contribution from the band arising from “ $\mathrm{M}=\mathrm{O}=\mathrm{M}$ " which resulted from the involvement of naphtholate oxygen atoms in bridge formation $[46,47]$.

Complexes (2) to (5) and (7) to (10) show a new but very weak intensity band in the region of $1076-1045 \mathrm{~cm}^{-1}$. This band is assigned to ring breathing mode of pyridine, 2picoline, 3-picoline, and 4-picoline molecules. The presence of this band in the IR spectra of complexes (2) to (5) and (7) to (10) indicates coordination of pyridine, 2-picoline, 3-picoline, and 4-picoline with the metal centre [48].

The antisymmetric and symmetric -OH stretching modes of lattice water appear in the region of 3500$3000 \mathrm{~cm}^{-1}$, while the $\mathrm{H}-\mathrm{O}-\mathrm{H}$ bending mode appears in the region of $1630-1610 \mathrm{~cm}^{-1}$. Coordinated water molecules besides showing the above two bands also show wagging and rocking modes in the region of $900-750 \mathrm{~cm}^{-1}$ which are activated by coordination with the metal centre [49].

\section{Conclusion}

Monometallic and homobimetallic $\mathrm{Ni}(\mathrm{II})$ complexes have been studied in the paper. The monometallic complexes (1) to (5) possess $\mu_{\text {eff }}$ value in the range of $2.85-3.45$ BM consistent with their octahedral stereochemistry while in complexes (6) to $(10) \mu_{\text {eff }}$ values lie in the range of $1.14-1.73 \mathrm{BM}$, that is, $0.57-$ 0.87 per $\mathrm{Ni}$ (II) ion, which are less than the values reported for spin-free $\mathrm{Ni}(\mathrm{II})$. These values rule out the possibility of any 


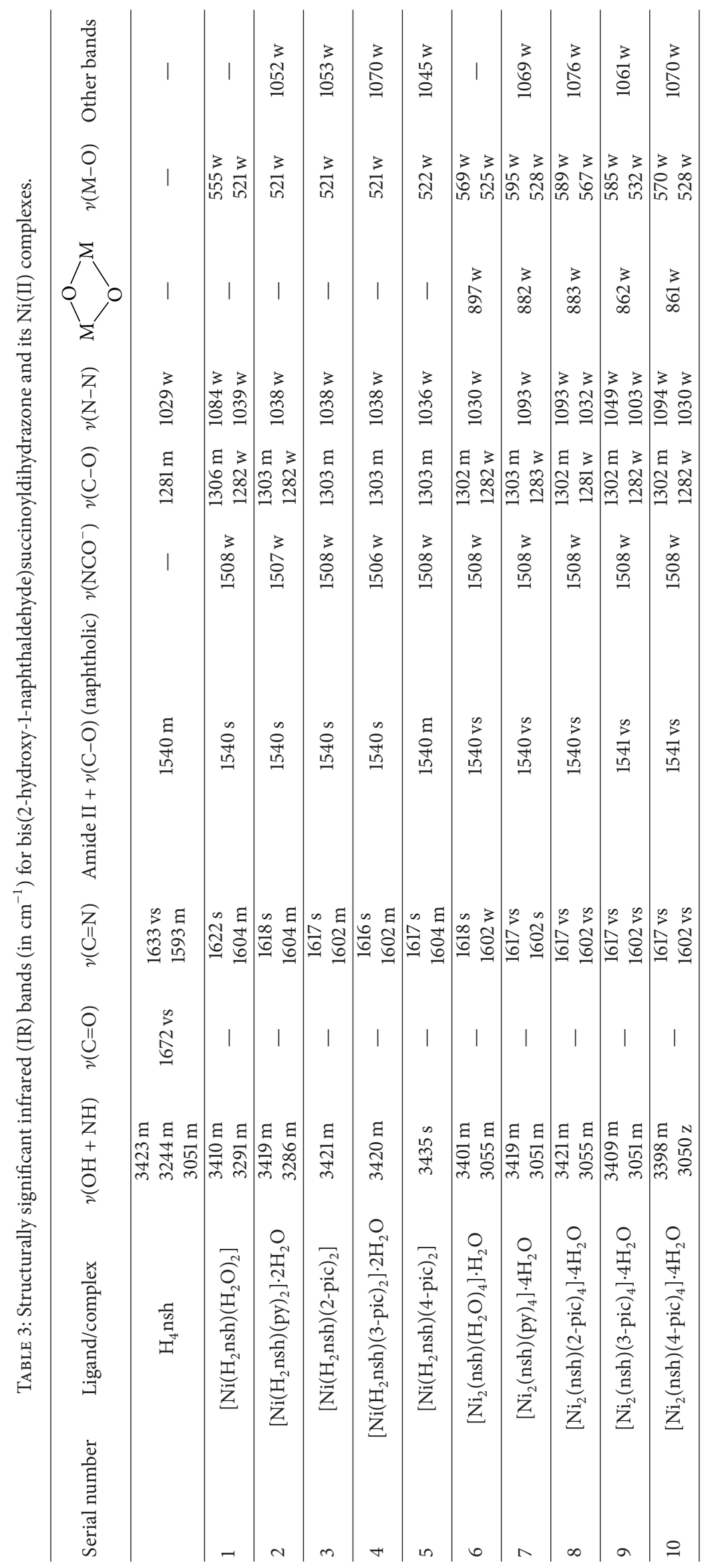




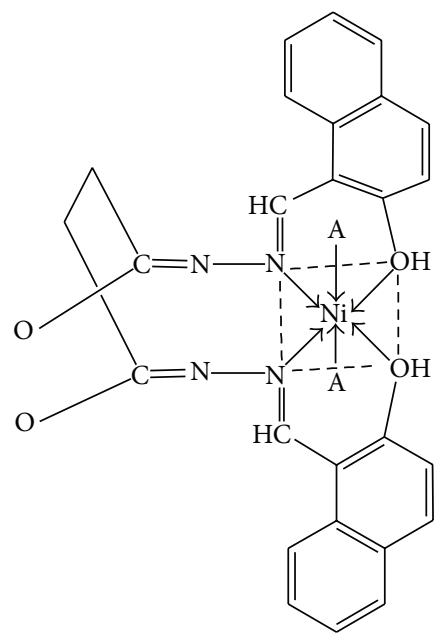

FIGURE 2: Tentative structure of $\left[\mathrm{Ni}_{(}\left(\mathrm{H}_{2} \mathrm{nsh}\right)(\mathrm{A})_{2}\right] \cdot n \mathrm{H}_{2} \mathrm{O}$ (where $\mathrm{A}=$ water $\left(\mathrm{H}_{2} \mathrm{O}\right), n=0$ (1); pyridine (py), $n=2$ (2); 2-picoline(2-pic), $n=0$ (3); 3-picoline(3-pic), $n=2$ (4); and 4-picoline(4-pic), $n=0$ (5)).

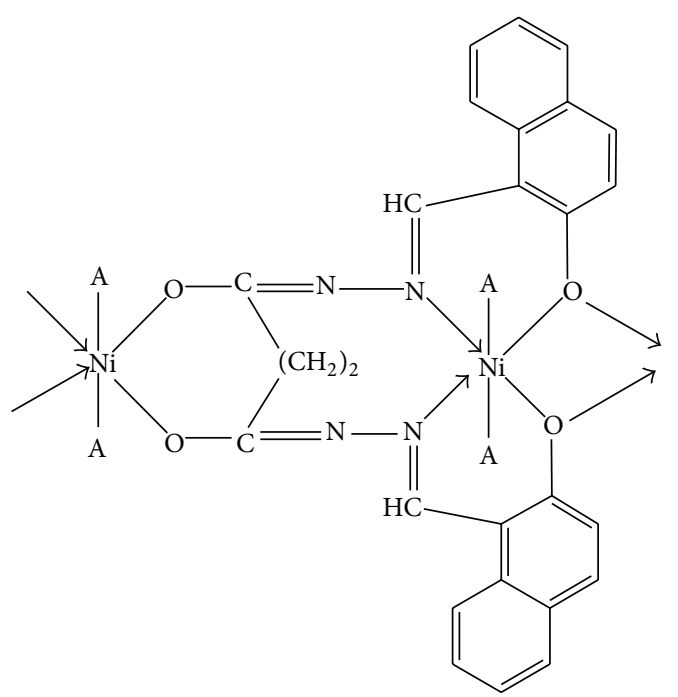

FIGURE 3: Tentative structure of $\left[\mathrm{Ni}_{2}(\mathrm{nsh})(\mathrm{A})_{4}\right] \cdot n \mathrm{H}_{2} \mathrm{O}$, where $\mathrm{A}=$ water $\left(\mathrm{H}_{2} \mathrm{O}\right), n=1$ (6); pyridine (py), $n=4$ (7); 2-picoline(2-pic), $n=4$ (8); 3-picoline(3-pic), $n=4$ (9); and 4-picoline(4-pic), $n=4$ (10).

metal-metal interaction in monometallic complexes while the values suggest strong metal-metal interaction in complexes (6)-(10). The dihydrazone $\left(\mathrm{H}_{4} \mathrm{nsh}\right)$ coordinates with the metal centre as a dibasic tetradentate ligand in enol form through azomethine nitrogen atoms and deprotonated naphtholic oxygen atoms in complexes (1)-(5). In these complexes, (1)-(5), the dihydrazone donor atoms are arranged around the $\mathrm{Ni}(\mathrm{II})$ centre in the equatorial position while the axial positions are occupied by the coligands $\mathrm{H}_{2} \mathrm{O}$ /pyridine/2picoline/3-picoline/4-picoline molecules. Electronic spectral studies suggest that all of the homobimetallic complexes (6)-(10) have distorted octahedral stereochemistry. In these complexes the ligand coordinates with the metal centre as a tetrabasic hexadentate ligand. One of the $\mathrm{Ni}(\mathrm{II})$ centres is present in $\mathrm{N}_{2} \mathrm{O}_{2}$ coordination sphere and another $\mathrm{Ni}(\mathrm{II})$ centre is bonded to it through phenolate oxygen atoms via oxo-bridging.

The tentative structures for the complexes have been shown in Figures 2 and 3.

\section{Conflict of Interests}

Authors declare that there is no conflict of interests regarding the publication of this research work.

\section{Acknowledgment}

Authors are grateful to the Head, SAIF, North-Eastern Hill University, Shillong, Meghalaya 793022, for CHN analyses and spectral studies.

\section{References}

[1] R. A. Lal, M. Chakrabarty, S. Choudhury, A. Ahmed, R. Borthakur, and A. Kumar, "Synthesis and spectral characterization of homobimetallic molybdenum(VI) complexes derived from bis(2-hydroxy-1-naphthaldehyde)succinoyldihydrazone," Journal of Coordination Chemistry, vol. 63, no. 1, pp. 163-175, 2010.

[2] R. A. Lal, M. Chakraborty, O. B. Chanu et al., "Synthesis and characterization of heterobimetallic $\mathrm{Ni}(\mathrm{II})-\mathrm{Zn}$ (II) complexes from bis(2-hydroxy-1 -naphthaldehyde)succinoyldihydrazone," Journal of Coordination Chemistry, vol. 63, no. 7, pp. 1239-1251, 2010.

[3] R. J. Angelici, "Heterogeneous catalysis of the hydrodesulfurization of thiophenes in petroleum: an organometallic perspective of the mechanism," Accounts of Chemical Research, vol. 21, no. 11, pp. 387-394, 1988.

[4] C. Belle, C. Bougault, M.-T. Averbuch et al., "Paramagnetic NMR investigations of high-spin nickel(II) complexes. Controlled synthesis, structural, electronic, and magnetic properties of dinuclear vs mononuclear species," Journal of the American Chemical Society, vol. 123, no. 33, pp. 8053-8066, 2001.

[5] F. Meyer and H. Pritzkow, "A bridging coordination mode of urea and carbamate at a dinuclear nickel(II) centre," Chemical Communications, no. 15, pp. 1555-1556, 1998.

[6] R. K. Andrews, R. L. Blakely, and B. Zerner, "Urea and urease," in Advances in Inorganic Biochemistry, G. L. Eichhorn and L. G. Marzilli, Eds., vol. 5, pp. 245-283, Elsevier, New York, NY, USA, 1984.

[7] S. Mandal, R. N. Bose, J. W. Reed, and E. S. Gould, "Electron transfer. 129. Copper Catalysis in the thiol reduction of oximebound nickel(IV)," Inorganic Chemistry, vol. 35, no. 11, pp. 31593162, 1996.

[8] Comprehensive Coordination Chemistry II, vol. 6, Elsevier, Pergamon, Turkey, 2004.

[9] E. Fujita, B. S. Brunschwig, T. Ogata, and S. Yanagida, “Toward photochemical carbon dioxide activation by transition metal complexes," Coordination Chemistry Reviews, vol. 132, pp. 195200, 1994. 
[10] E. Kimura, S. Wada, M. Shiongya, and Y. Okazaki, "New series of multifunctionalized nickel(II)-cyclam (cyclam $=1,4,8,11-$ tetraazacyclotetradecane) complexes. Application to the photoreduction of carbon dioxide," Inorganic Chemistry, vol. 33, pp. 770-778, 1994.

[11] S. Pal and S. Pal, "Ruthenium(II) complexes containing $\mathrm{RuN}_{4} \mathrm{O}_{2}$ spheres assembled via pyridine-imine-amide coordination. Syntheses, structures, properties and protonation behaviour of coordinated amide," Journal of the Chemical Society, Dalton Transactions, no. 9, pp. 2102-2108, 2002.

[12] R. Dinda, P. Sengupta, S. Ghosh, H. Mayer-Figge, and W. S. Sheldrick, "A family of mononuclear molybdenum-(VI), and (IV) oxo complexes with a tridentate (ONO) ligand," Journal of the Chemical Society, Dalton Transactions, no. 23, pp. 44344439, 2002.

[13] G. A. Al-Hazmi and A. A. El-Asmy, "Synthesis, spectroscopy and thermal analysis of copper(II) hydrazone complexes," Journal of Coordination Chemistry, vol. 62, no. 2, pp. 337-345, 2009.

[14] R. Dinda, P. Sengupta, S. Ghosh, and W. S. Sheldrick, "Synthesis, structure, and reactivity of a new mononuclear molybdenum(VI) complex resembling the active center of molybdenum oxotransferases," European Journal of Inorganic Chemistry, vol. 2003, no. 2, pp. 363-369, 2003.

[15] M. K. Singh, N. K. Kar, and R. A. Lal, "Synthesis and characterization of manganese(IV) and ruthenium(III) complexes derived from bis(2-hydroxy-1-naphthaldehyde)oxalyl dihydrazone," Journal of Coordination Chemistry, vol. 61, no. 19, pp. 3158-3171, 2008.

[16] R. A. Lal, D. Basumatary, S. Adhikari, and A. Kumar, "Synthesis and properties of mononuclear and binuclear molybdenum complexes derived from bis(2-hydroxy-1-naphthaldehyde)oxaloyldihydrazone," Spectrochimica Acta-Part A: Molecular and Biomolecular Spectroscopy, vol. 69, no. 3, pp. 706-714, 2008.

[17] L. Zhao, V. Niel, L. K. Thompson et al., "Self-assembled polynuclear clusters derived from some flexible polydentate dihydrazide ligands," Dalton Transactions, no. 9, pp. 1446-1455, 2004.

[18] M. Carcelli, S. Ianelli, P. Pelagatti et al., "Synthesis and characterization of new lanthanide complexes with hexadentate hydrazonic ligands," Inorganica Chimica Acta, vol. 358, no. 4, pp. 903-911, 2005.

[19] S. Naskar, D. Mishra A, and S. K. Chattopadhyay, "Synthesis, characterization, and crystal structure of $\left[\operatorname{Ni}\left(\operatorname{dap}(\mathrm{A})_{2}\right)\right]_{2}$ (dap $(\mathrm{AH})_{2}$ : 2,6-diacetylpyridine bis(anthraniloyl hydrazone)) - a molecule possessing an infinite double helical chain in the solid state," Structural Chemistry, vol. 18, no. 2, pp. 217-222, 2007.

[20] J. D. Ranford, J. J. Vittal, and Y. M. Wang, "Dicopper(II) complexes of the antitumor analogues acylbis(salicylaldehyde hydrazones) and crystal structures of monomeric $\left[\mathrm{Cu}_{2}(1,3\right.$-propanedioyl bis(salicylaldehyde hydrazone $\left.)\left(\mathrm{H}_{2} \mathrm{O}\right)_{2}\right] \cdot\left(\mathrm{ClO}_{4}\right)_{2} \cdot 3 \mathrm{H}_{2} \mathrm{O}$ and polymeric $\left[\mathrm{Cu}_{2}\right.$ (1,6-hexanedioyl bis(salicylaldehyde hydrazone)). $\left.\left(\mathrm{C}_{2} \mathrm{H}_{5} \mathrm{OH}\right)_{2 m}\right] \cdot\left(\mathrm{ClO}_{4}\right)_{2 m} \cdot m\left(\mathrm{C}_{2} \mathrm{H}_{5} \mathrm{OH}\right)$," Inorganic Chemistry, vol. 37, no. 6, pp. 1226-1231, 1998.

[21] R. C. Aggarwal and K. K. Narang, "N-acetyl, N'-benzoyl hydrazine complexes of cobalt(II), nickel(II) and copper(II)," Inorganica Chimica Acta, vol. 7, pp. 651-652, 1973.

[22] R. A. Lal, A. N. Siva, S. Adhikari, M. K. Singh, and U. S. Yadav, "Synthesis and spectral characterization of dioxouranium(VI) complexes of disalicylaldehyde adipoyldihydrazone," Synthesis and Reactivity in Inorganic and Metal-Organic Chemistry, vol. 26, no. 2, pp. 321-337, 1996.

[23] F. Feigl, V. Anger, and R. E. Oesper, Spot Tests in Organic Analysis, Elsevier, Amsterdam, The Netherlands, 7th edition, 1966, Indian Reprint 2005.

[24] R. A. Lal, S. Adhikari, A. Pal, A. N. Siva, and A. Kumar, "Synthesis and characterization of the homobimetallic [bis(2hydroxy-1-naphthaldehyde)oxaloyldihydrazonato]bis(dioxomolybdenum(VI)) tetrahydrate complex and its reactivity towards proton and electron donor reagents," Journal of Chemical Research-Part S, no. 4, pp. 122-123, 1997.

[25] W. J. Geary, "The use of conductivity measurements in organic solvents for the characterisation of coordination compounds," Coordination Chemistry Reviews, vol. 7, no. 1, pp. 81-122, 1971.

[26] T. M. A. Ismail, "Mononuclear and binuclear $\mathrm{Co}(\mathrm{II}), \mathrm{Ni}(\mathrm{II})$, $\mathrm{Cu}(\mathrm{II}), \mathrm{Zn}(\mathrm{II})$ and $\mathrm{Cd}(\mathrm{II})$ complexes of Schiff-base ligands derived from 7-formyl-8-hydroxyquinoline and diaminonaphthalenes," Journal of Coordination Chemistry, vol. 58, no. 2, pp. 141-151, 2005.

[27] M. Shakir, Y. Azim, H. T. N. Chishti, N. Begum, P. Chingsubam, and M. Y. Siddiqi, "Synthesis, physico-chemical and antimicrobial screening studies on 14 and 16-membered hexaazamacrocyclic complexes bearing pendant amine groups," Journal of the Brazilian Chemical Society, vol. 17, no. 2, pp. 272-278, 2006.

[28] S. C. Nyburg and J. S. Wood, "The molecular structures of Lifschitz nickel(II) complexes. II. The crystal structures of one of the blue and of one of the yellow forms of bis(mesostilbenediamine)nickel(II) dichloroacetate," Inorganic Chemistry, vol. 3, no. 4, pp. 468-476, 1964.

[29] V. V. Savant, J. Gopalakrishnan, and C. C. Patel, "Metal monothiobenzoates," Inorganic Chemistry, vol. 9, no. 4, pp. 748-751, 1970.

[30] H. L. Nigam and K. B. Pandeya, "On mixed stereochemistry of a binuclear nickel-thiovanol complex," Current Science, vol. 41, no. 12, pp. 449-451, 1972.

[31] W. Levason and C. A. McAuliffa, "Bidentate group VB chelates. Part XV. Four- and five-coordinate cobalt(II) complexes of very soft donors. Planar coordination," Inorganica Chimica Acta, vol. 14, pp. 127-132, 1975.

[32] R. L. Dutta and M. Hossain, "Coordination chemistry of acyl, aroyl, heteroaroyl hydrazones and related ligands," Journal of Scientific and Industrial Research, vol. 44, no. 12, pp. 635-674, 1985.

[33] M. Mohan, N. K. Gupta, M. Kumar, N. K. Jha, and W. E. Antholine, "Synthesis, magnetic and electrochemical properties of binuclear copper(II) complexes of pyridoxal hydrazones," Inorganica Chimica Acta, vol. 197, no. 1, pp. 39-46, 1992.

[34] S. C. Chan, L. L. Koh, P.-H. Leung, J. D. Ranford, and K. Y. Sim, "Copper(II) complexes of the antitumour-related ligand salicylaldehyde acetylhydrazone $\left(\mathrm{H}_{2} \mathrm{~L}\right)$ and the single-crystal X-ray structures of $\left[\mathrm{Cu}(\mathrm{HL}) \mathrm{H}_{2} \mathrm{O}_{2}\right] \cdot 2\left(\mathrm{NO}_{3}\right)$ and $[\mathrm{Cu}(\mathrm{HL})$ (pyridine) $\left(\mathrm{NO}_{3}\right)_{2}$ ]," Inorganica Chimica Acta, vol. 236, no. 1-2, pp. 101-108, 1995.

[35] T. N. Sorrell, "Synthetic models for binuclear copper proteins," Tetrahedron, vol. 45, no. 1, pp. 3-68, 1989.

[36] Y. Shijo, T. Shimizu, and K. Sakai, "Extractive spectrophotometric determination of antimony(III), bismuth, indium, and gallium with pyrocatechol violet and tridodecylethylammonium bromide," Bulletin of the Chemical Society of Japan, vol. 56, no. 1, pp. 105-107, 1983.

[37] N. Al-Awadi, N. M. Shuaib, and A. El-Dissouky, "Synthesis and spectroscopic characterization of nickel(II) complexes 
of 1-benzotriazol-1-yl-[(p-X-phenyl)hydrazone]propan-2-one," Spectrochimica Acta Part A: Molecular and Biomolecular Spectroscopy, vol. 65, no. 1, pp. 36-43, 2006.

[38] A. B. P. Lever, "Electronic spectra of some transition metal complexes: derivation of $\mathrm{D}_{q}$ and B," Journal of Chemical Education, vol. 45, no. 11, pp. 711-712, 1968.

[39] B. Adhikary, S. Liu, and C. R. Lucas, "Comparative studies of mononuclear nickel(II) complexes with $\mathrm{N}_{2} \mathrm{Sx}(\mathrm{x}=2-4)$ ligands," Inorganic Chemistry, vol. 32, no. 26, pp. 5957-5962, 1993.

[40] A. B. P. Lever, "The electronic spectra of tetragonal metal complexes analysis and significance," Coordination Chemistry Reviews, vol. 3, no. 2, pp. 119-140, 1968.

[41] Z. H. Abd El-Wahab, "Mononuclear metal complexes of organic carboxylic acid derivatives: synthesis, spectroscopic characterization, thermal investigation and antimicrobial activity," Spectrochimica Acta Part A: Molecular and Biomolecular Spectroscopy, vol. 67, no. 1, pp. 25-38, 2007.

[42] P. K. Radhakrishnan, P. Indrasenan, and C. G. R. Nair, "Complexes of lanthanide nitrates with $4 \mathrm{n}$-(2'-hydroxy benzylidene)aminoantipyrine," Polyhedron, vol. 3, no. 1, pp. 67-70, 1984.

[43] R. K. Agarwal and J. Prakash, "Synthesis and characterization of thorium(IV) and dioxouranium(VI) complexes of pentamethylene sulphoxide," Polyhedron, vol. 10, no. 22, pp. 2567-2571, 1991.

[44] G. G. Mohamed and C. M. Sharaby, "Metal complexes of Schiff base derived from sulphametrole and o-vanilin. Synthesis, spectral, thermal characterization and biological activity," Spectrochimica Acta-Part A: Molecular and Biomolecular Spectroscopy, vol. 66, no. 4-5, pp. 949-958, 2007.

[45] R. Gup and B. Kirkan, "Synthesis and spectroscopic studies of copper(II) and nickel(II) complexes containing hydrazonic ligands and heterocyclic coligand," Spectrochimica Acta Part A: Molecular and Biomolecular Spectroscopy, vol. 62, no. 4-5, pp. 1188-1195, 2005.

[46] W. P. Griffith, C. A. Pumphrey, and T.-A. Rainey, "Catecholato complexes of ruthenium, iridium, rhenium, molybdenum, and tungsten," Journal of the Chemical Society, Dalton Transactions, pp. 1125-1128, 1986.

[47] A. M. El-Hendawy, W. P. Griffith, and C. A. Pumphrey, "Complexes of osmium, uranium, molybdenum, and tungsten with the catechol amines adrenaline, noradrenaline, dopamine, dopa, and isoproterenol," Journal of the Chemical Society, Dalton Transactions, no. 7, pp. 1817-1821, 1988.

[48] R. A. Lal, M. L. Pal, and S. Adhikari, "Synthesis, characterization and some properties of oxoperoxo complexes of molybdenum with 2-hydroxy-1-naphthaldehyde isonicotinoylhydrazone," Synthesis and Reactivity in Inorganic and MetalOrganic Chemistry, vol. 26, no. 6, pp. 997-1023, 1996.

[49] G. Sartori, C. Furlani, and A. Damiani, "On the problem of the vibrational frequencies of water in complexes," Journal of Inorganic and Nuclear Chemistry, vol. 8, pp. 119-125, 1958. 

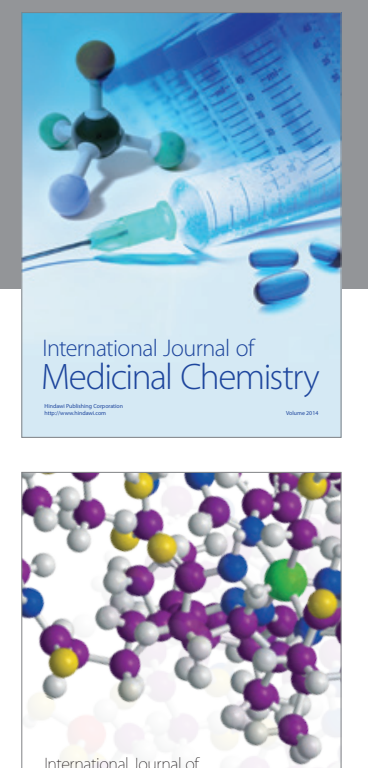

\section{Carbohydrate} Chemistry

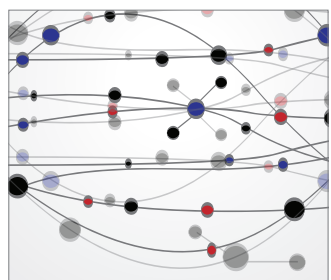

The Scientific World Journal
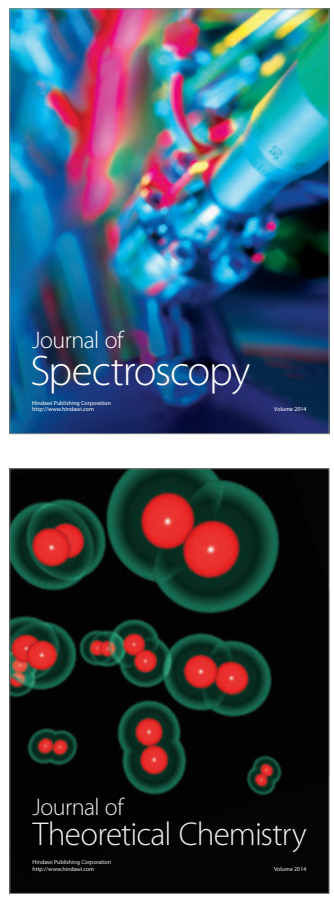
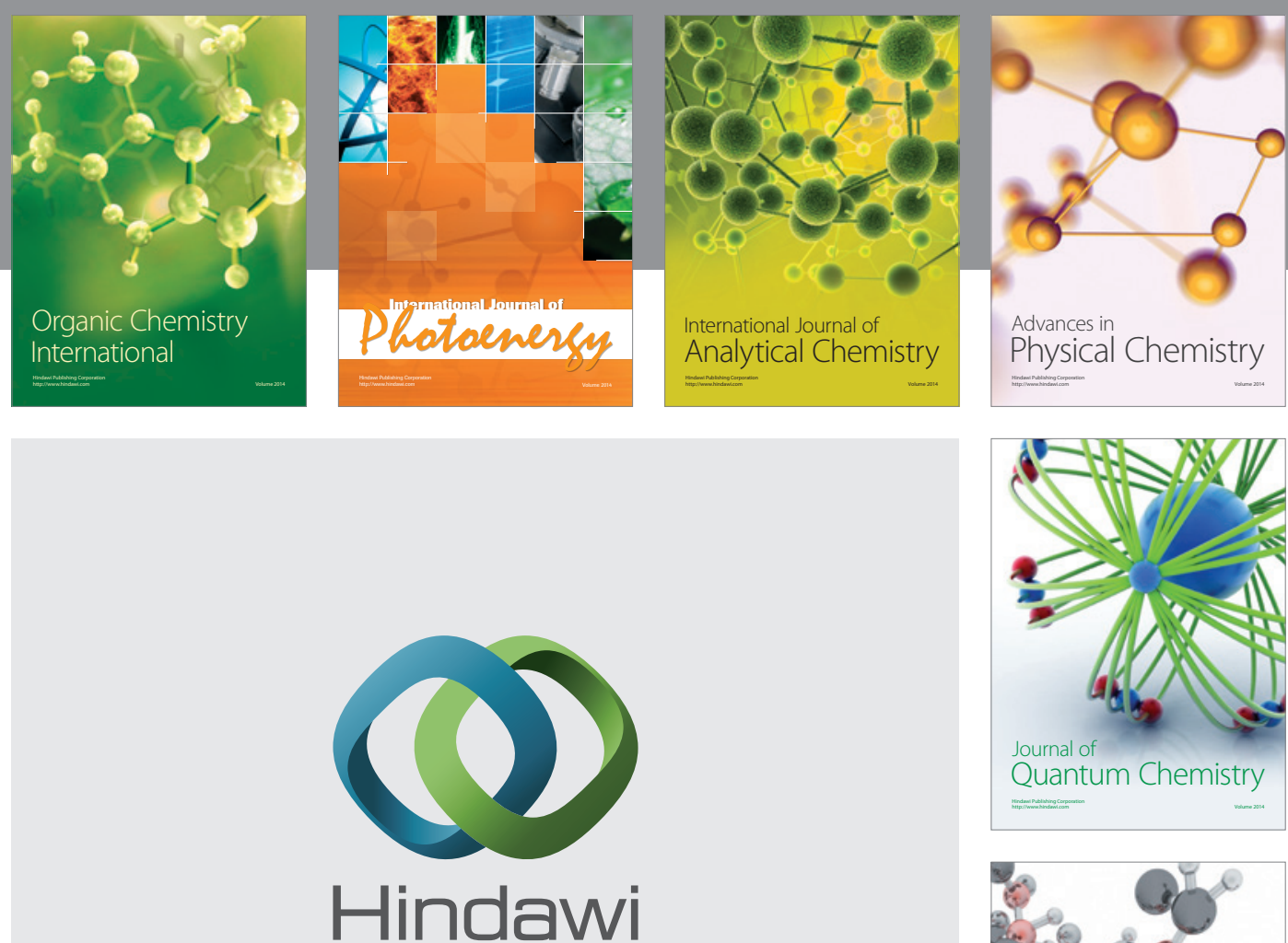

Submit your manuscripts at

http://www.hindawi.com

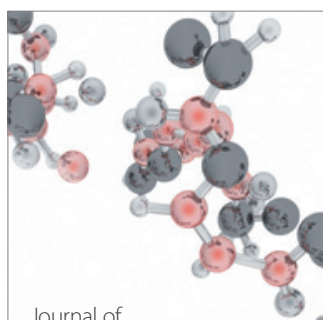

Analytical Methods

in Chemistry

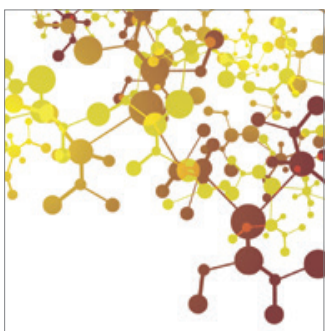

Journal of

Applied Chemistry

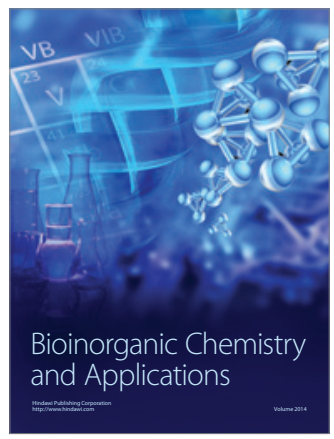

Inorganic Chemistry
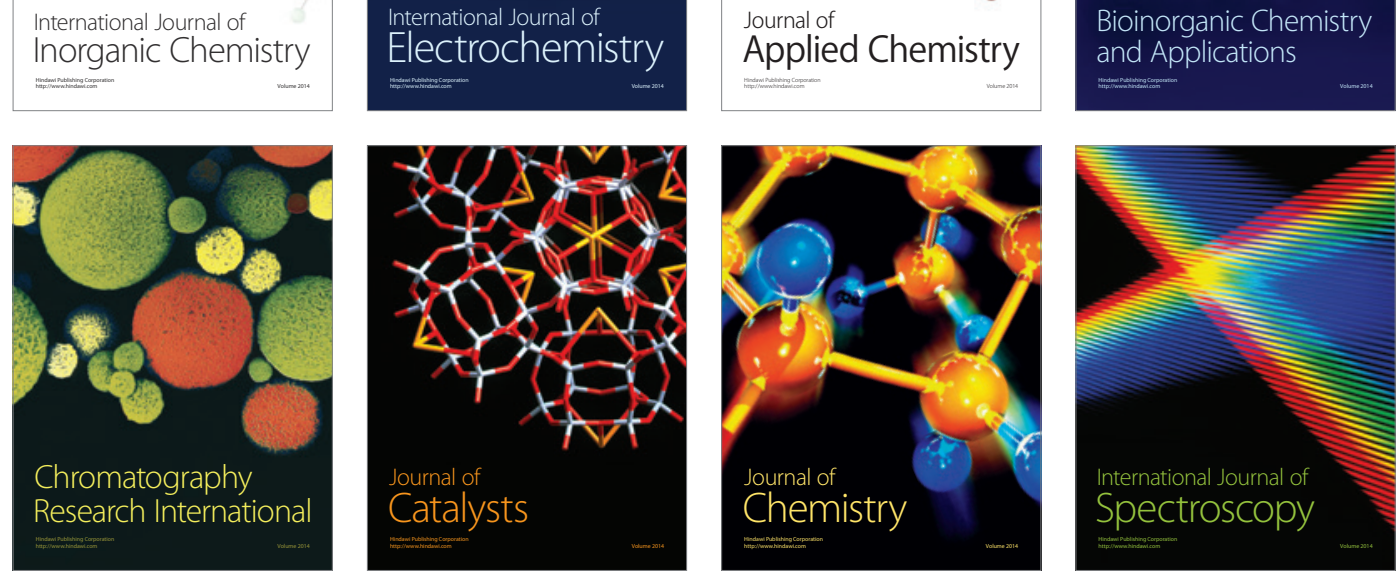